Arq. Bras. Med. Vet. Zootec., v.70, n.2, p.545-553, 2018

\title{
Estudo metanalítico da resposta de gramíneas perenes de verão à adubação nitrogenada
}

[Meta-analytic study of response of nitrogen fertilization on perennial summer grasses]

\author{
A. Bernardi, A.W.L. Silva, D. Baretta
}

Universidade do Estado de Santa Catarina - UDESC - Chapecó, SC

\section{RESUMO}

O presente trabalho visou empregar um estudo metanalítico para sumarizar e analisar dados sobre adubação nitrogenada em pastagens formadas por gramíneas dos gêneros Brachiaria, Cynodon e Panicum. Foram selecionados 36 trabalhos de pesquisa realizados no Brasil nos últimos 10 anos, incluindo artigos científicos, teses e dissertações. Com base nos dados contidos nesses trabalhos, foi calculado o incremento relativo de matéria seca e de proteína bruta em relação ao tratamento controle (ausência de adubação nitrogenada) e a eficiência da utilização do nitrogênio na produção de matéria seca e proteína bruta. Os dados obtidos foram submetidos à análise de variância para efeito linear e quadrático em cada uma das variáveis dentro de cada gênero e, no caso de significância, foi realizada análise de regressão. A produção de matéria seca e de proteína bruta de forrageiras tropicais responde de forma expressiva à adubação nitrogenada, principalmente a segunda, porém o acréscimo nas doses de nitrogênio reduz a eficiência da adubação. Verificou-se uma frequente omissão de informações relevantes em trabalhos com adubação nitrogenada em pastagens.

Palavras-chave: metanálise, eficiência da adubação, forrageiras tropicais, nitrogênio

\begin{abstract}
The study aimed to employ a meta-analytic study to summarize and analyze data on nitrogen fertilization in grasslands formed by grasses of the genera Brachiaria, Cynodon and Panicum. A sample of 36 research projects carried out in Brazil in the last ten years, including scientific papers, theses and dissertations were selected. From the data contained in these works, relative dry matter and crude protein increment compared to the control treatment (absence of nitrogen fertilization) and the efficiency of nitrogen use in the production of dry matter and crude protein were calculated. Data were subjected to analysis of variance for linear and quadratic effect on each variable within each genus and, in case of significance, regression analysis was performed. The production of dry matter and crude protein of tropical forages responds greatly to nitrogen fertilization, especially the second, but the increase in nitrogen rates reduces the efficiency of fertilization. There was a frequent omission of relevant information in scientific works on nitrogen fertilization in grasslands.
\end{abstract}

Keywords: meta-analysis, fertilization efficiency, tropical grasses, nitrogen

\section{INTRODUÇÃO}

Em sistemas de produção pecuária sobre pastagens tropicais, faz-se necessário incrementar a disponibilidade de nitrogênio $(\mathrm{N})$ a fim de se obter elevada produção de matéria seca (MS) e incremento no valor nutritivo, particularmente no teor de proteína bruta $(\mathrm{PB})$ (Campos et al., 2016), e, como consequência, ampliar a carga animal que a área suporta (Assmann et al., 2004). Porém, a resposta à adubação nitrogenada é limitada por diversos fatores, como o teor de matéria orgânica no solo, a disponibilidade de água (Di Nasso et al., 2015; Gomes et al., 2015), a forma de aplicação, a época do ano (Iwamoto et al., 2014), as condições climáticas (Campos et al., 2016), o potencial da planta, o intervalo entre cortes (Oliveira et al., 2011; Flores et al., 2012), as interações com os demais nutrientes (Cadisch et al., 1994), entre outros elementos. Em determinadas condições, doses mais elevadas de

Recebido em 18 de outubro de 2016

Aceito em 14 de março de 2017

E-mail: aleb09@hotmail.com 
nitrogênio podem não representar incremento em produtividade devido às perdas desse elemento (Rowlings et al., 2016), o que reduz a economicidade e aumenta o impacto ambiental sobre o agroecossistema.

Existem diversos trabalhos avaliando a resposta de forrageiras tropicais perenes à fertilização nitrogenada. Entretanto, um experimento isolado traduz apenas o efeito dos tratamentos nas condições específicas em que foi realizado (StPierre, 2007), o que restringe a aplicabilidade dos resultados obtidos. Já um estudo metanalítico permite sumarizar os dados de vários trabalhos e, portanto, fornece conclusões de forma mais ampla, às quais se pode atribuir um maior grau de confiabilidade.

Este trabalho objetiva analisar a resposta de gramíneas forrageiras dos gêneros Brachiaria, Cynodon e Panicum à adubação nitrogenada, em termos de produção de matéria seca, de proteína bruta e eficiência do uso do nitrogênio, tendo por base experimentos realizados no Brasil.

\section{MATERIAL E MÉTODOS}

Para seleção dos trabalhos científicos, foi realizada uma revisão sistemática, utilizando-se, como base de dados, o Google Scholar, escolhido devido à sua reconhecida acessibilidade e à abrangente disponibilidade de trabalhos científicos brasileiros. A busca foi operacionalizada nos meses de março e abril de 2016, de forma individualizada para os três gêneros botânicos, empregando-se, como palavras-chave, os nomes genéricos Brachiaria, Cynodon e Panicum, bem como suas principais espécies e cultivares. A coleta restringiu-se aos trabalhos mencionados nas 20 primeiras páginas da base de dados, para cada sessão de busca, e envolveu apenas pesquisas realizadas no Brasil e publicadas/editadas na forma de artigos científicos completos, dissertações e teses, no intervalo entre 2006 e 2016.

O processo de busca resultou na identificação de 129 trabalhos, que constituíram a amostra primária do estudo. Após análise pormenorizada de cada material, verificou-se a necessidade de proceder-se a descartes, motivados por ausência de dados sobre produção de MS (52 trabalhos), experimentos realizados em vasos (16 trabalhos), experimentos envolvendo outras espécies em consorciação às gramíneas (sete trabalhos), emprego de apenas dois tratamentos experimentais (sete trabalhos), falta de informações, tais como intervalo entre cortes, número de cortes e unidades de medida (oito trabalhos) e, por fim, valores ilegíveis (três trabalhos). Assim, 36 trabalhos compuseram a amostra final (Tab.1), dos quais um envolveu os três gêneros, 14 o gênero Brachiaria (66 tratamentos e 236 parcelas), nove o gênero Cynodon (43 tratamentos e 159 parcelas) e 12 o gênero Panicum (59 tratamentos e 213 parcelas).

As variáveis analisadas foram obtidas diretamente dos dados expostos no trabalho ou calculadas com base neles. Todas foram avaliadas em função da dose aplicada de nitrogênio e do gênero da forrageira.

Eficiência da adubação nitrogenada na produção de matéria seca (EMS): obtida mediante a divisão da produção total de MS pelo total de nitrogênio aplicado.

Acréscimo de MS em relação ao controle, em porcentagem (PMS\%): esse valor foi obtido por meio da fórmula $\left(P M S_{\text {dose }}-P M S_{\text {cntrl }}\right) / P M S_{\text {cntrl }}$, em que $P M S_{\text {dose }}$ é a produção em MS em determinada dose de nitrogênio e $P M S_{\text {cntrl }}$ referese à produção de MS no tratamento controle (dose zero de nitrogênio). Alguns trabalhos (três com Brachiaria, um com Cynodon e quatro com Panicum) não tinham tratamento controle e foram descartados desta análise.

Eficiência da adubação nitrogenada na produção de proteína bruta (EPB): obtida mediante a divisão da produção total de PB pelo total de nitrogênio aplicado. Quatro trabalhos com Brachiaria, seis com Cynodon e nove com Panicum não participaram desta análise, pois não analisavam o teor de proteína bruta.

Acréscimo de $\mathrm{PB}$ em relação ao controle, em porcentagem (PPB\%): obtido por meio da fórmula: $\left(P B_{\text {dose }}-P B_{\text {cntrl }}\right) / P B_{\text {cntrl }}$, em que $P B_{\text {dose }}$ é a produção de $\mathrm{PB}$ em uma determinada dose de nitrogênio e $P B_{\text {cntrl }}$ refere-se à produção de $\mathrm{PB}$ no tratamento controle (dose zero de nitrogênio). Dos trabalhos que continham análise de proteína bruta, um com Cynodon e um com Panicum não apresentavam tratamento controle e, portanto, não fizeram parte desta análise. 
Tabela 1. Relação dos trabalhos empregados na metanálise

\begin{tabular}{|c|c|}
\hline Alencar, C. A. B. et al. & Revista Brasileira de Saúde e Produção Animal, v.11, P.48-58, 2010 \\
\hline Andrade, A. C. et al. & Revista Científica de Produção Animal, v.11, P.1-14, 2009 \\
\hline Bernardino, F. S. et al. & Revista Brasileira de Zootecnia, v.40, P.1412-1419, 2011 \\
\hline Cabral, W. B. et al. & Revista Brasileira de Zootecnia, v.41, P.846-855, 2012 \\
\hline Canto, M. W. et al. & Revista Brasileira de Zootecnia, v.38, P.1176-1182, 2009 \\
\hline Corrêa, L. A. et al. & Revista Brasileira de Zootecnia, v.36, P.763-772, 2007 \\
\hline Costa, K. A. P. et al. & Arq. Bras. de Med. Veterinária e Zootecnia, v.62, P.192-199, 2010 \\
\hline Cunha, O. F. R. et al. & Revista da FZVA, v.17, P136-145, 2010 \\
\hline Deminicis, B. B. et al. & Ciência Agrotécnica., v.34, P.1116-1123, 2010 \\
\hline Fagundes, J. L. et al. & Revista Brasileira de Zootecnia, v.40, P.2651-2657, 2011 \\
\hline Gomes, E. P. et al. & Revista Bras. Engenharia Agrícola e Ambiental, v.19, P.317-323, 2015 \\
\hline Iwamoto, B. S. et al. & Bioscience Journal, v.30, P.530-538, 2014 \\
\hline Magalhães, A. F. et al. & Revista Brasileira de Zootecnia, v.36, P.1240-1246, 2007 \\
\hline Magalhães, M. A. et al. & Revista Brasileira de Zootecnia, v.40, P.2308-2317, 2011 \\
\hline Mazza, L. M. et al. & Scientia Agraria, v.10, P.257-265, 2009 \\
\hline Mesquita, E. E. et al. & Revista Brasileira de Saúde e Produção Animal, v.9, P.201-209, 2008 \\
\hline Oliveira, M. A. et al. & Arq. Bras. de Med. Veterinária e Zootecnia, v.63, P.694-703, 2011 \\
\hline Pinheiro, A. A. et al. & Semina: Ciências Agrárias, v.35, P.2147-2158, 2014 \\
\hline Quaresma, J. P. S. et al. & Acta Scientiarum. Animal Sciences, v.33, P.145-150, 2011 \\
\hline Ribeiro, O. L. et al. & Revista Brasileira de Saúde e Produção Animal, v.12, P.275-285, 2011 \\
\hline Simões, C. R. et al. & Ciência Rural, v.45, P.697-703, 2015 \\
\hline Viana, M. A. C. et al. & Revista Brasileira de Zootecnia, v.40, P.1497-1503, 2011 \\
\hline Vitor, C. M. T. et al. & Boletim de Indústria Animal, v.68, P.62-69, 2011 \\
\hline Almeida, F. M. & Dissertação (Mestrado), Ufes, 55P., 2014 \\
\hline Crociolli, C. A. & Dissertação (Mestrado), Unesp, 72P., 2008 \\
\hline Dupas, E. & Dissertação (Mestrado), Unesp, 43P., 2008 \\
\hline Fernandes, J.C. & Dissertação (Mestrado), Unesp, 52P., 2011 \\
\hline Galzerano, L. & Dissertação (Mestrado), UFRRJ, 39P., 2008 \\
\hline Leal, D. M. & Dissertação (Mestrado), UFG, 103P., 2014 \\
\hline Parra, F. B. G. & Dissertação (Mestrado), Unesp, 58P., 2009 \\
\hline Pires, C. A. & Dissertação (Mestrado), 80P., 2014 \\
\hline Santini, J. M. K. & Dissertação (Mestrado), Unesp, 70P., 2014 \\
\hline Silva, R. P. & Dissertação (Mestrado), UFRRJ, 62P., 2012 \\
\hline Strozzi, G. & Dissertação (Mestrado), USP, 71P., 2014 \\
\hline Silva, I. P. & Tese (Doutorado), Ufla, 96P., 2013 \\
\hline Soares Filho, C. V. & Tese (Doutorado), Unesp, 103P., 2008 \\
\hline
\end{tabular}

Foram realizadas análises de variância e, posteriormente, análise de regressão dos dados de cada variável dentro de cada gênero. Nas variáveis e espécies em que houve significância linear ou quadrática, foram determinadas as equações de regressão, de acordo com o modelo que melhor se ajustou. As análises de variância e de regressão foram realizadas com auxílio do software estatístico $\mathrm{SAEG}^{\circledR}$, versão 8.0, ao nível de $5 \%$ de probabilidade $(\mathrm{P}<0,05)$. $\mathrm{O}$ cálculo da equação de regressão foi feito com auxílio do software Microsoft Excel ${ }^{\circledR} 2010$.

\section{RESULTADOS E DISCUSSÃO}

Foi observado aumento linear na produção de matéria seca (PMS\%) e de proteína bruta (PPB\%) em relação ao controle $(\mathrm{P}<0,05)$ para Brachiaria e Panicum (Tab. 2, Fig. 1 e 2). Esse resultado evidencia a efetividade da adubação nitrogenada, pois, mesmo com as variadas condições em que os trabalhos sumarizados foram realizados, nota-se resposta consistente ao N. Tal resultado deve-se à notável capacidade de gramíneas tropicais de produzir MS, pois seu metabolismo C4 favorece a incorporação de 
carbono para compor seus tecidos, potencial esse que, em muitos casos, é limitado pela oferta de nitrogênio (Howden et al., 1999). Além disso, a adubação nitrogenada também está relacionada com o aumento da produção de proteína, uma vez que proporciona mais $\mathrm{N}$ para a síntese proteica $\mathrm{e}$ intensifica o desenvolvimento das folhas (Alexandrino et al., 2004; Siva et al., 2009; Cabral et al., 2012), estruturas com maior teor proteico.

Tabela 2. Valores de $\mathrm{P}$ encontrados nas variáveis estudadas para efeito linear (L) e quadrático (Q) e coeficientes de variação (CV) das doses de adubação nitrogenada na forma mineral

\begin{tabular}{|c|c|c|c|c|c|c|c|c|c|}
\hline & \multicolumn{3}{|c|}{ Brachiaria } & \multicolumn{3}{|c|}{ Cynodon } & \multicolumn{3}{|c|}{ Panicum } \\
\hline & \multicolumn{2}{|c|}{$\mathrm{P}$} & \multirow{2}{*}{$\mathrm{CV}$} & \multicolumn{2}{|c|}{$\mathrm{P}$} & \multirow{2}{*}{$\mathrm{CV}$} & \multicolumn{2}{|c|}{$\mathrm{P}$} & \multirow{2}{*}{$\mathrm{CV}$} \\
\hline & $\mathrm{L}$ & Q & & $\mathrm{L}$ & Q & & $\mathrm{L}$ & Q & \\
\hline PMS\% & 0,002 & NS & $72 \%$ & 0,18 & 0,16 & $102 \%$ & 0,04 & NS & $43 \%$ \\
\hline EMS & 0,009 & NS & $35 \%$ & 0,01 & 0,02 & $54 \%$ & 0,04 & NS & $47 \%$ \\
\hline РPB\% & 0,002 & 0,11 & $59 \%$ & 0,12 & 0,24 & $64 \%$ & 0,03 & NS & $44 \%$ \\
\hline EPB & 0,052 & NS & $53 \%$ & 0,03 & NS & $48 \%$ & NS & NS & $79 \%$ \\
\hline
\end{tabular}

PMS\%: produção de matéria seca determinada pela adubação nitrogenada em relação à produção de matéria seca do tratamento controle, EMS: eficiência da adubação nitrogenada, PPB\%: produção de proteína bruta determinada pela adubação nitrogenada em relação à produção de proteína bruta do tratamento controle e EPB: eficiência da adubação nitrogenada.

A produção de proteína bruta (PB) calculada neste trabalho é produto da multiplicação do teor de $\mathrm{PB}$ e da produção de matéria seca em função das doses de nitrogênio diferentes artigos sumarizados. Isso acarretou um ganho relativo de proteína bruta em relação ao controle mais acentuado que o de matéria seca, como pode ser observado ao se compararem as Fig. 1 e 2, uma vez que o nitrogênio age elevando os dois fatores dessa multiplicação.

Ademais, cabe ressaltar que o resultado encontrado neste trabalho é em produção de proteína bruta por área. A resposta em concentração de proteína bruta à adubação nitrogenada é menos evidente que a de produção de matéria seca (Mesquita, Neres, 2008; Deminicis et al., 2010), pois esse aspecto sofre maior limitação da variabilidade genética, uma vez que a herdabilidade da primeira pode variar entre 0,66 e 0,74 (Vogel et al., 1981; Figueiredo et al., 2012) e a da segunda está entre 0,47 e 0,57 (Jiang et al., 2014; Mateus et al., 2015; Simeão et al., 2016).

Por outro lado, não houve resposta estatística no gênero Cynodon para PMS\% e PPB\%. Como as espécies do gênero Cynodon naturalmente apresentam maior concentração de PB em relação à Brachiaria e ao Panicum (Soares Filho et al., 2002), uma mesma resposta percentual em relação ao controle, ou sem uso de nitrogênio (PPB\%), para esse gênero depende de um aumento na proteína mais expressivo que dos outros dois, enquanto a falta de resposta estatística para PMS\% no gênero Cynodon é relativa ao coeficiente de variação elevado encontrado (102\%). 


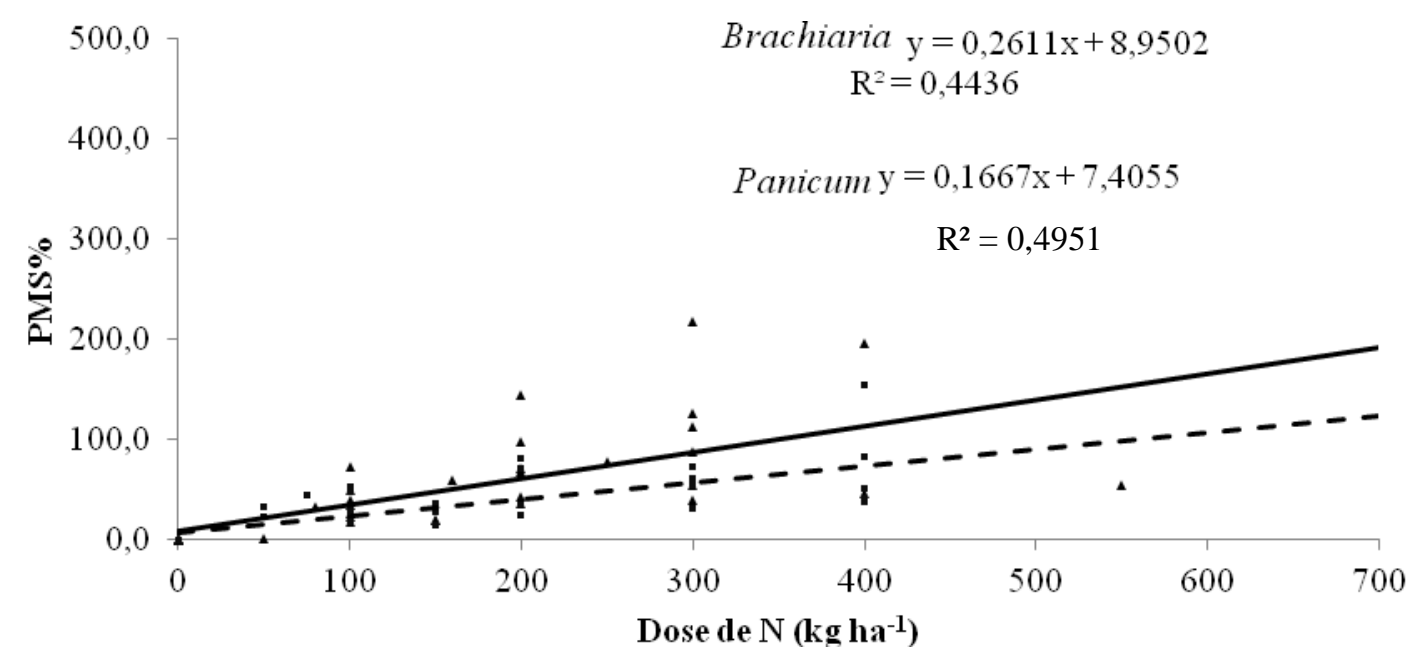

Figura 1. Dispersão dos dados e curvas de regressão de ganho de matéria seca (\%) em relação ao controle para Brachiaria e Panicum.

PMS\%: acréscimo de matéria seca $(\%)$ em relação ao controle; ( $\boldsymbol{\Delta})$ dispersão dos dados do gênero Brachiaria; ( $\mathbf{\square}$ ) dispersão dos dados do gênero Panicum; (-) curva estimada de acréscimo de matéria seca em relação ao controle (\%) com o acréscimo de nitrogênio via adubação para Brachiaria e (---) para Panicum.

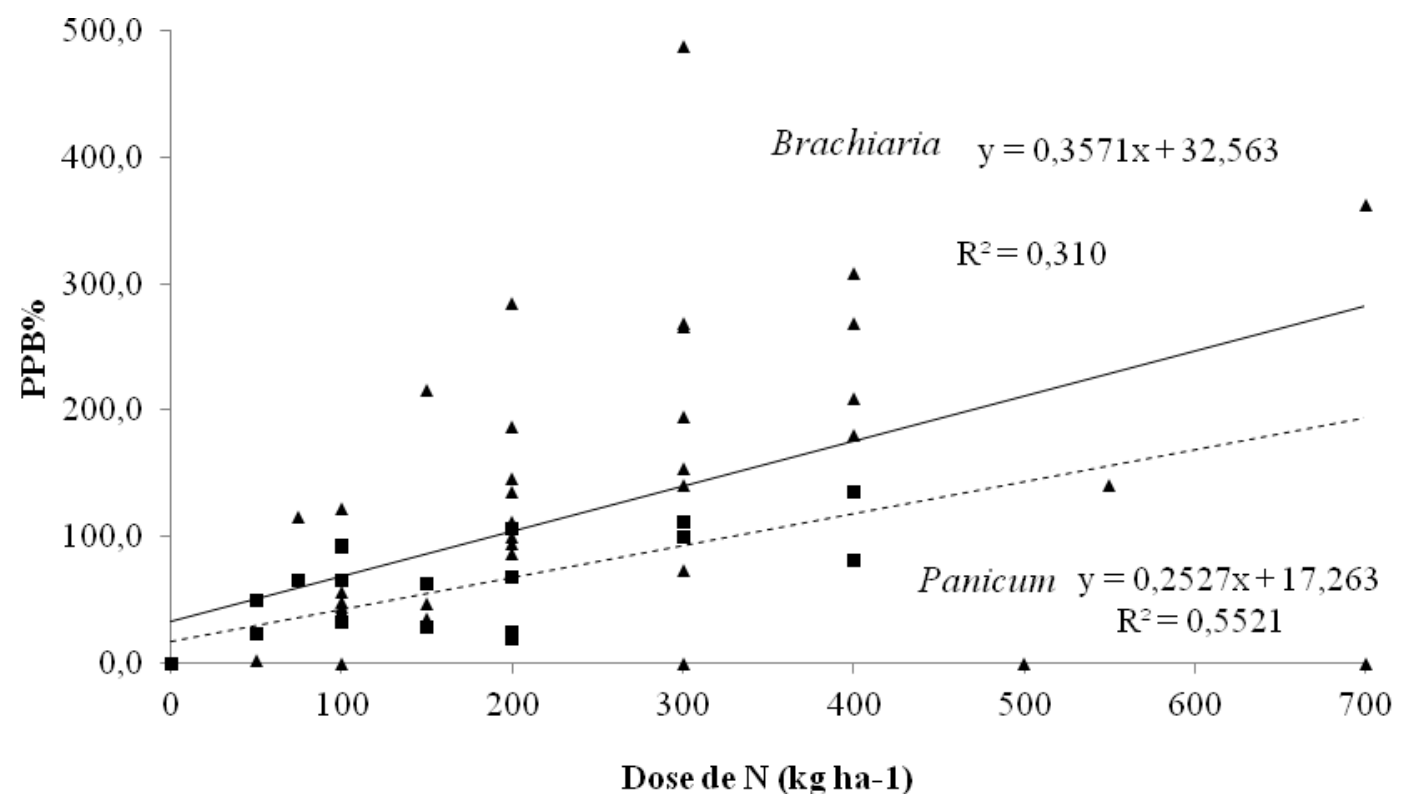

Figura 2. Dispersão dos dados e curvas de regressão do acréscimo de proteína bruta (\%) em relação ao controle para Brachiaria e Panicum.

PPB\%: acréscimo de proteína bruta $(\%)$ em relação ao controle; $(\boldsymbol{\Delta})$ dispersão dos dados do gênero Brachiaria; (ם) dispersão dos dados do gênero Panicum; (--) curva estimada de acréscimo de proteína bruta (\%) em relação ao controle para Brachiaria e (---) para Panicum. 
A eficiência do uso do $\mathrm{N}$ para a produção de matéria seca (EMS) ou de proteína bruta (EPB) mostrou resultados diferentes (Tab. 2). No primeiro parâmetro, houve efeito significativo (Fig. 3) para Brachiaria e Panicum (linear) e para Cynodon (quadrático). Já na EPB ocorreu apenas significância linear para Cynodon (Fig. 4). Isso indica que, em Brachiaria e Panicum, a eficiência de conversão da adubação nitrogenada em produção de proteína bruta se mantém constante com o aumento da dose na adubação, fazendo com que a reta da EPB em função da dose de nitrogênio seja horizontal. Esse resultado é atribuído à magnitude da resposta de produção de proteína bruta (PPB\%) para esses dois gêneros, mesmo nas doses mais elevadas de nitrogênio. Tal efeito nas doses mais altas possivelmente se deve mais ao aumento na produção de MS do que no teor de PB, já que o primeiro parâmetro apresenta menor herdabilidade, como já visto, e, portanto, está sujeito à maior influência ambiental. Por outro lado, para Cynodon não houve resultado estatístico para PPB\%, o que, como citado, sugere menor influência da adubação nesse quesito para esse gênero e explica a diminuição linear da EPB em função da dose de nitrogênio.

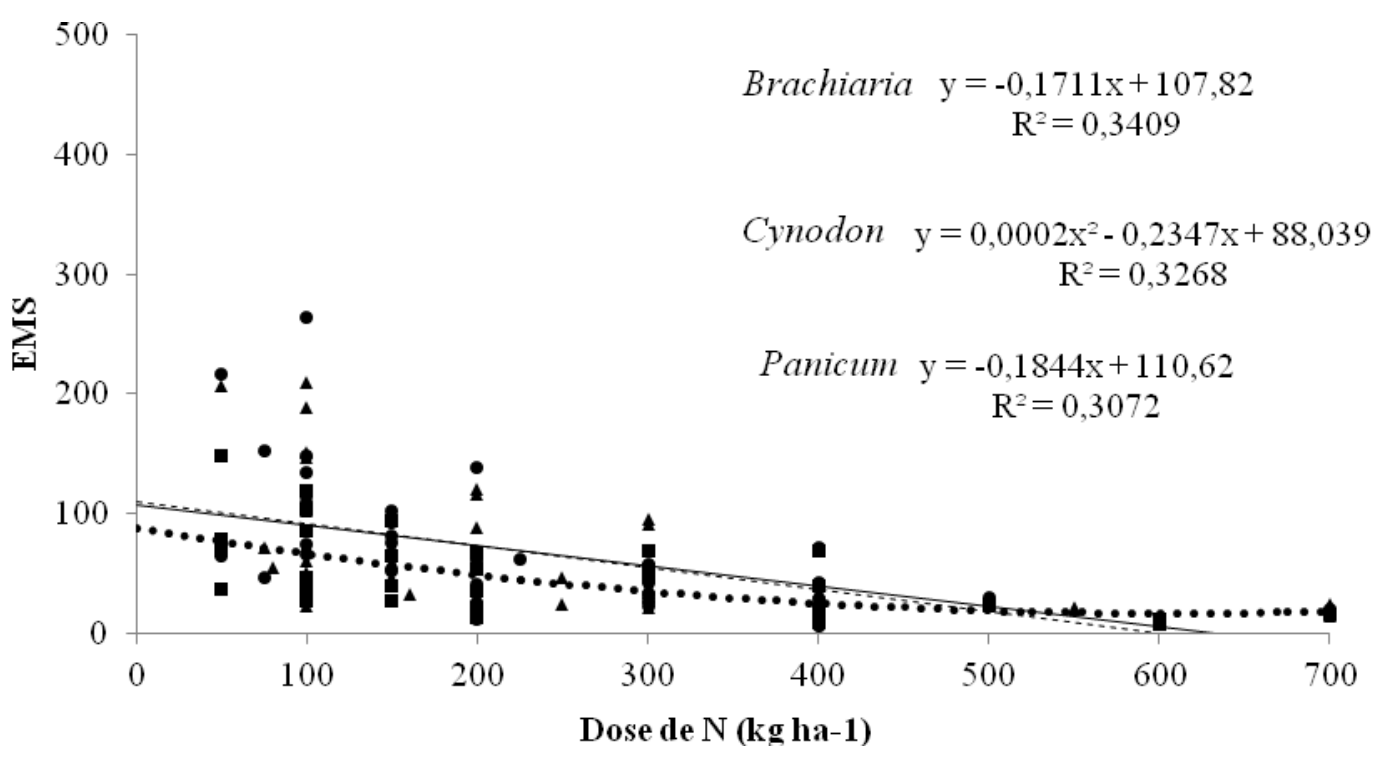

Figura 3. Dispersão dos dados e curvas de regressão da eficiência da adubação nitrogenada (MS / kg de N $\mathrm{ha}^{-1}$ ) na produção de matéria seca para Brachiaria, Cynodon e Panicum.

EMS: eficiência da adubação nitrogenada; $(\boldsymbol{\Delta})$ dispersão dos dados do gênero Brachiaria; $(\boldsymbol{O})$ dispersão dos dados do gênero Cynodon; ( $\mathbf{\square}$ ) dispersão dos dados do gênero Panicum; (-) curva estimada de eficiência da adubação nitrogenada em função de doses crescentes de nitrogênio via adubação para Brachiaria, (..) para Cynodon e (---) para Panicum.

Resultados que demonstram redução na eficiência da adubação com o aumento das doses de nitrogênio são comuns (Quaresma et al., 2011; Rowlings et al., 2016), porém também pode ser encontrada resposta quadrática, com aumento da eficiência até um certo patamar e posterior queda (Castagnara et al., 2011). A divergência dos resultados na literatura está ligada à capacidade da planta em absorver e acumular $\mathrm{N}$ em seus tecidos, sob mediação de condições climáticas e da disponibilidade do elemento no solo. O N da adubação mineral é rapidamente disponível para as plantas na solução do solo, mas o $\mathrm{N}$ que não é absorvido pelas raízes é perdido por lixiviação ou volatização, ou então incorporado à matéria orgânica do solo. Os resultados deste trabalho atestam quedas consistentes na eficiência do $\mathrm{N}$, principalmente na produção de MS, o que pode ser devido aos fatores listados acima, mas também à duração relativamente curta dos experimentos sumarizados (em média, 183 \pm 123 
dias), além da possibilidade de o $\mathrm{N}$ aplicado ter sido retido na matéria orgânica, sendo liberado por mais de um ano (Rowlings et al., 2016). Entretanto, também ao compararem diversos resultados de pesquisa, Martha Júnior et al.
(2004) observaram eficiência média da adubação nitrogenada inferior (26 de $\mathrm{MS} / \mathrm{kg}$ de $\mathrm{N}$ ) à encontrada no presente trabalho $(60 \mathrm{~kg}$ de $\mathrm{MS} / \mathrm{kg}$ de N).

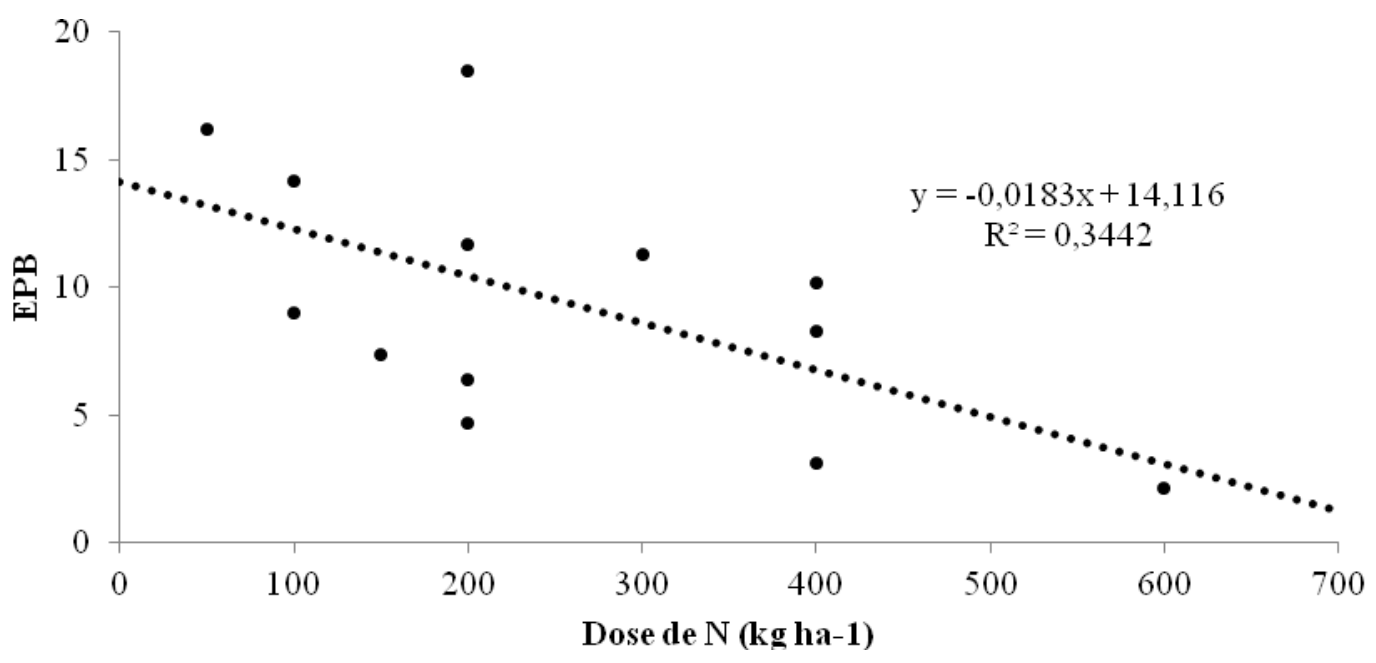

Figura 4. Dispersão dos dados e curvas de regressão da eficiência da adubação nitrogenada na produção de proteína bruta $\left(\mathrm{PB} / \mathrm{kg}\right.$ de $\left.\mathrm{N} \mathrm{ha}^{-1}\right)$ para Cynodon.

EPB: eficiência da adubação nitrogenada na produção de proteína bruta; ( $)$ dispersão dos dados do gênero Cynodon; (...) curva estimada de eficiência da adubação nitrogenada em função de doses crescentes de nitrogênio via adubação para Cynodon.

É importante ter cautela com os resultados lineares encontrados. Mesmo que já tenham sido reportadas respostas lineares em produção de MS e na concentração de PB sob doses superiores a $600 \mathrm{~kg}$ de $\mathrm{N} \mathrm{ha}^{-1}$ (Campos et al., 2016), salientase que, nesta metanálise, foram sumarizados poucos trabalhos com doses acima de $500 \mathrm{~kg}$ de $\mathrm{N} \mathrm{ha}^{-1}$, o que proporcionou um número reduzido de observações nessas doses (cinco, três e duas, respectivamente, para Brachiaria, Cynodon e Panicum). Trabalhos com doses dessa magnitude são pouco frequentes, pois não refletem o que é praticado no campo.

Chama a atenção a carência de informações em parte dos trabalhos coletados na busca inicial. Como citado anteriormente, a maior parte dos trabalhos não foi utilizada para a análise por falta de informações, em especial no tocante à produção de MS, o que causa estranheza, uma vez que se trata da principal resposta de uma forrageira à adubação nitrogenada. Mesmo entre os trabalhos selecionados para a análise, foi observada a ausência de informações importantes, como o tipo de solo (ausente em $22,5 \%$ dos trabalhos) e o teor de matéria orgânica no solo (ausente em 30\% dos trabalhos), fatores esses que exercem interferência direta no resultado de experimentos que avaliam adubação nitrogenada.

\section{CONCLUSÃO}

A adubação nitrogenada acarreta aumentos consistentes na produção de matéria seca e de proteína bruta, com um efeito mais acentuado na segunda. À vista disso, conhecidas a importância nutricional e a econômica da proteína, a adubação nitrogenada se mostra ainda mais relevante nos sistemas de produção, pelo aumento da oferta desse nutriente. Entretanto, a eficiência do uso do nitrogênio é inversamente proporcional ao aumento nas doses de nitrogênio, sendo necessário encontrar um ótimo econômico. 


\section{REFERÊNCIAS}

ALEXANDRINO, E.; NASCIMENTO JÚNIOR, D.; MOSQUIN, P.R. et al. Características morfogênicas e estruturais na rebrotação da Brachiaria brizantha cv. Marandu submetida a três doses de nitrogênio. Rev. Bras. Zootec., v.33, p.1372-1379, 2004.

ASSMANN, A.L.; PELISSARI, A.; MORAES A. et al. Produção de gado de corte e acúmulo de matéria seca em sistema de integração lavourapecuária em presença e ausência de trevo branco e nitrogênio. Rev. Bras. Zootec., v.33, p.37-44, 2004

CABRAL, W.B.; SOUZA, A.L.; ALEXANDRINO, E. et al. Características estruturais e agronômicas da Brachiaria brizantha cv. Xaraés submetida a doses de nitrogênio. Rev. Bras. Zootec., v.41, p.846-855, 2012.

CADISCH, G.; GILLER, K.E.; URQUIAGA, S. et al. Does phosphorus supply enhance soil-N mineralization in Brazilian pastures? Eur. J. Agron., v.3, p.339-345, 1994.

CAMPOS, F.P.; NICÁCIO, D.R.O.; SARMENTO, P. et al. Chemical composition and in vitro ruminal digestibility of hand-plucked samples of Xaraes palisade grass fertilized with incremental levels of nitrogen. Anim. Feed Sci. Technol., v.215, p.1-12, 2016.

CASTAGNARA, D.D.; ZOZ, T.; KRUTZMANN, A. et al. Produção de forragem, características estruturais e eficiência de utilização do nitrogênio em forrageiras tropicais sob adubação nitrogenada. Semin. Cienc. Agrar., v.32, p.1617-1648, 2011.

DEMINICIS, B.B.; ABREU, J.B.R.; VIEIRA, H.D.; ARAÚJO, S.A.C. Brachiaria humidicola (Rendle) Schweick em diferentes idades de rebrota submetida a doses de nitrogênio e potássio. Cienc. Agrotec., v.34, p.1116-1123, 2010.

DI NASSO, N.N.; LASORELLA, M.; RONCUCCIA, N.; BONARIA, E. Soil texture and crop management affect switchgrass (Panicum virgatum L.) productivity in the Mediterranean. Ind. Crop. Prod., v.65, p.21-26, 2015.
FIGUEIREDO, U.J.; NUNES, J.R.; VALLE, C.B. Estimation of genetic parameters and selection of Brachiaria humidicola progenies using a selection index. Crop Breed. Appl. Biotechnol., v.12, p.237-244, 2012.

FLORES, R.A.; URQUIAGA, S.S.; ALVES, B.J.R. et al. Adubação nitrogenada e idade de corte na produção de matéria seca do capimelefante no Cerrado. Rev. Bras. Eng. Agríc. Ambient., v.16, p.1282-1288, 2012.

GOMES, E.P.; RICKLI, M.E.; CECATO, U. et al. Produtividade de capim Tifton 85 sob irrigação e doses de nitrogênio. Rev. Bras. Eng. Agríc. Ambient., v.19, p.317-323, 2015.

HOWDEN, S.M.; MCKEON, G.M.; WALKER, L. et al. Global change impacts on native pastures in south-east Queensland, Australia. Environ. Modell. Softw., v.4, p.307-316, 1999.

IWAMOTO, B.S.; CECATO, U; RIBEIRO, O.L. et al. Produção e composição morfológica do capim-tanzânia fertilizado com nitrogênio nas estações do ano. Bioscience, v.30, p.530-538, 2014.

JIANG, Q.; WEBB, S.L.; YESUDAS, C.R. et al. Variance components and heritability of biomass yield in switchgrass (Panicum virgatum L.) grown in the Southern Great Plains. Field Crops Res., v.168, p.148-155, 2014.

MARTHA JÚNIOR, G.B.; VILELA， L.; BARIONI, L.G. et al. Manejo da adubação nitrogenada em pastagens. In: PEDREIRA, C.G.S.; MOURA, J.C.; FARIA, V.P. (Eds.). Fertilidade do solo para pastagens produtivas. Piracicaba: FEALQ, 2004. p.155-217.

MATEUS, R.G.; BARRIOS, S.C.L.; VALLE, C.B. et al. Genetic parameters and selection of Brachiaria decumbens hybrids for agronomic traits and resistance to spittlebugs. Crop Breed. Appl. Biotechnol., v.15, p.227-234, 2015.

MESQUITA, E.E.; NERES, M.A. Morfogênese e composição bromatológica de cultivares de Panicum maximum em função da adubação nitrogenada. Rev. Bras. Saúde Prod. Anim., v.9, p.201-209, 2008.

OLIVEIRA, M.A.; PEREIRA, O.G.; RIBEIRO, K.G. et al. Produção e valor nutritivo do capimcoastcross sob doses de nitrogênio e idades de rebrotação. Arq. Bras. Med. Vet. Zootec., v.63, p.694-703, 2011. 
QUARESMA, J.P.S.; ALMEIDA, R.G.; ABREU, J.G. et al. Produção e composição bromatológica do capim-tifton 85 (Cynodon spp.) submetido a doses de nitrogênio. Acta Sci. Anim. Sci., v.33, p.145-150, 2011.

ROWLINGS, D.W.; SCHEER, C.; LIU, S.; GRACEA, P.R. Annual nitrogen dynamics and urea fertilizer recoveries from a dairy pasture using $15 \mathrm{~N}$; effect of nitrification inhibitor DMPP and reduced application rates. Agric. Ecosyst. Environ., v.216, p.216-225, 2016.

SILVA, CC.F.; BONOMO, P.; PIRES, A.J.V. et al. Características morfogênicas e estruturais de duas espécies de braquiária adubadas com diferentes doses de nitrogênio. Rev. Bras. Zootec., v.38, p.657-661, 2009.
SIMEÃO, R.; SILVA, A.; VALLE, C.; RESENDE M.D., MEDEIROS, S. Genetic evaluation and selection index in tetraploid Brachiaria ruziziensis. Plant Breed., v.135, p.246-253, 2016.

SOARES FILHO, C.V.; RODRIGUES, L.RA.; PERRI, S.H.V. Produção e valor nutritivo de dez gramíneas forrageiras na região Noroeste do Estado de São Paulo. Acta Sci., v.24, p.13771384, 2002.

ST-PIERRE, N.R. Meta-analyses of experimental data in the animal sciences. Rev. Bras. Zootec., v.36, p.343-358, 2007.

VOGEL, K.P.; GORZ, H.J.; HASKINS, F.A. Heritability estimates for forage yield, in vitro dry matter digestibility, crude protein, and heading date in indiangrass. Crop Sci., v.21, p.35-38, 1981. 